\title{
EVALUASI PROGRAM PEMBINAAN PRESTASI BELA DIRI SHOTO-KAI KABUPATEN NAGEKEO
}

\author{
Bernabas Wani \\ Pendidikan Jasmanai Kesehatan dan Rekreasi STKIP Citra Bakti \\ Email: bernabas.wani@gmail.com
}

\begin{abstract}
Abstrak
Peneltian ini bertujuan untuk 1) Untuk mengevaluasi bagaimana konteks prestasi bela diri shotokai kabupaten Nagekeo, 2) Untuk mengevaluasi bagaimana input yang meliputi sumber daya manusia, kualitas dan ketersediaan sarana dan prasarana, Sumber dana pembinaan prestasi bela diri shotokai kabupaten Nagekeo, 3) Untuk mengevaluasi bagaimana proses program pembinaan olahraga bela diri sotokai kabupaten Nagekeo, 4) Untuk mengevaluasi bagaimana hasil pembinaan olahraga bela diri shotokai kabupaten Nagekeo.Teknik pengumpulan data adalah observasi, wawancara, dokumentasi dan triangulasi data. Hasil dari penelitian ini ialah 1) context yang meliputi visi, misi, tujuan pembinaan sotokai kabupaten Nagekeo dikatakan baik karena mempunyai semuanya dari aspek yang ada 2) Input yang meliputi sumber daya manusia, sarana prasana dan dana. Pelatih yang ada pada sotokai kabupaten Nagekeo mempunyai standar yang baik karena pelatih memiliki lisensi pelatih tingkat nasional serta mempunyai atlet, sarana prasarana yang masih sangat kurang sehingga mempengaruhi tingkat prestasi dari atlet shotokai Nagekeo. Dana bersumber dari dukungan pemerintah daerah Kabupaten Nagekeo. 3) Proses yang meliputi pelaksanan program dan koordinasi, pelaksanaan program latihan pada cabang olahraga shotokai Nagekeo baik karena mempunyai program latihan yang baik, koordinasi antara pemerintah, pelatih dan atlet berjalan baik. 4) product, prestasi atlet sotokai kurang dan menurun ditandai dengan perolehan medali pada setiap kejuaran. Kesimpulannya bahwa dilihat dari aspek contex, input, proses dan product semuanya belum pada standar yang baik selayaknya pada pembinaan olahraga prestasi pada umumnya.
\end{abstract}

Kata Kunci: evaluasi, program pembinaan prestasi, shoto-kai

\begin{abstract}
This research aimed at (1) evaluating how the context of the Shoto-kai martial art achievement in Nagekeo regency.(2) evaluating how the input involved human resources, the quality and availability of facilities and infrastructure, the source of funds for the Shoto-kai martial art achievements founding in Nagekeo regency 3) evaluating how the process of the Shoto-kai martial art achievement founding program in Nagekeo regency, 4) evaluating how the results of Shoto-kai martial arts founding in Nagekeo regency. Data collection techniques were observation, interview, documentation and triangulation data. The result of this this research was 1) context which involved vision, mission, the purpose of Shoto-kai founding in Nagekeo regency was said to be good because it has everything from the existing aspects 2) Input that included human resources, infrastructure and funds. Shoto-kai trainers in Nagekeo regency have good standards because the trainer has a national trainer license and has athletes, infrastructure facilities that were still very less so it affected the performance level of Shoto-kai athletes in Nagekeo. Funding came from the support of regional government in Nagekeo regency, 3) Process that involved implementation
\end{abstract}


and coordination program, the implementation of Shoto-kai training programs branch sports in Nagekeo were good because it has a good training program, good coordination between the government, coaches and athletes. 4) product, the achievement of sotokai athletes was less and decreased marked by the achievement of medals in each championship. The conclusion was that from all aspects of context, input, process and product were not being in a good standard as appropriate in the achievement of sports founding in general

Keywords: evaluation, achievement training program, shoto-kai

\section{PENDAHULUAN}

Keberhasilan pembinaan prestasi sangat ditentukan oleh berbagai macam unsur, salah satu unsur yang berpengaruh terhadap pencapaian tujuan pembinaan prestasi adalah penerapan manajemen yang baik. Sehubungan dengan manajemen dalam pembinaan prestasi olahraga, ada lima sumber daya manajemen yang harus dikelola dengan baik, yaitu (1) sumber daya manusia, (2) kemampuan keuangan, (3) kerja sama internal, (4) sarana dan prasarana, (5) metode yang diterapkan. Kelima sumber daya manajemen diatas merupakan satu kesatuan yang tidak dapat dipisahkan satupersatu, karena satu sama lain saling mendukung dan saling menentukan. (Harsuki, 2012:64-65) Pembinaan dan pembangunan olahraga prestasi dilaksanakan dan diarahkan untuk mencapai prestasi pada tingkat daerah, nasional dan internasional. Pembinaan dilakukan oleh induk organisasi cabang olahraga baik pada tingkat daerah maupun pada tingkat pusat. Pembinaan dan pengembangan olahraga prestasi olahraga prestasi bertujuan untuk meningkatkan kemampuan dan potensi olahragawan dalam rangka meningkatkan harkat dan martabat bangsa (Undang-Undang Nomor 3 tahun 2007). Proses pembinaan atas dasar perhitungan usia, prestasi puncak cabang olahraga bulutangkis dapat dicapai sekitar umur 20 sampai 25 tahun, dan permulaan berolahraga pada usia 11-12 tahun (Bompa, 1994:34). Berarti untuk berprestasi dalam cabang olahraga inkai, pembibitan sejak usia dini harus dilaksnakan dengan konsisten, berkesinambungan, mendasar, sistematis, efisien dan terpadu. Untuk itu perlu membiasakan agar anak-anak ingin bermain dan berolahraga sejak usia dini sehingga dapat memacu perkembangan organ tubuhnya, dan dengan pendekatan yang persuasif anak-anak usia dini tersebut dapat berminat menjadi atlet. Olahraga shotokai sekarang sudah berkembang dengan pesatnya, baik di dunia maupun di 
Indonesia sendiri. Pembinaan prestasi di Nagekeo Provinsi NTT terdapat dojo dan dojan olahraga bela diri Sotokai yang di kelola atau dibina oleh swasta maupun pemerintah,

Pembinaan olahraga

prestasi tidak bisa berjalan dengan cara instan apalagi dengan manajemen asal jalan tetapi membutuhkan totalitas dan komitmen untuk membina olahraga secara sistemik dan mendukung (sustainable). Prestasi olahraga merupakan sesuatu yang obserable dan measurable, artinya bahwa pembinaan olahraga dilakukan dengan scientific approach mulai dari pemanduan bakat hingga proses pembinaan. Ketika di lihat dari kacamata kesisteman bahwa kualitas hasil (output) ditentukan oleh masukan (input) dan kualitas proses pembinaan yang terjadi. Prestasi yang selama ini di dapatkan merupakan konsekuensi nyata dari sub-sistem yang kurang optimal yaitu input dan proses Pembinaan prestasi olahraga membutuhkan proses untuk dapat mencapai prestasi puncak dan pembinaan atletpun tidak bisa dilakukan sendiri-sendiri, namun harus secara sistemik, terpadu, terarah dan terprogram dengan jelas (Bernabas Wani: 2018)

Persaingan untuk memajukan olahraga di setiap daerah sudah mulai terasa khususnya pada olahraga bela diri shotokai. Pada saat ini sangat dirasakan oleh shotokai kabupaten Nagekeo di bahwa kemajuan ilmu pengetahuan dan teknologi serta persaingan yang cukup ketat dalam cabang olahraga shotokai membuat prestasi menurun.

Penelitian ini bermaksud hendak mengkaji masalah pembinaan olahraga bela diri shotokai yang dilaksanakan oleh sotokai kabupaten Nagekeo untuk mengetahui secara komprehensif penyebab - penyebab menurunnya prestasi yang dimiliki oleh atletatlet yang berada di dojo shotokai kabupaten Nagekeo maka peneliti tertarik untuk meneliti fenomenafenomena yang terjadi di sotokai kabupaten Nagekeo "bagaimana pembinaan olahraga bela diri sotokai tersebut.

Tujuan evaluasi ada yang bersifat umum dan bersifat khusus. Zaenal Arifin (2009:13) mengatakan tujuan umum dinyatakan dalam rumusan umum sedangkan tujuan khusus dinyatakan dalam rumusan khusus dan terbatas, serta merupakan rincian dari tujuan umum

Dalam melakukan evaluasi penelitian ini menggunakan evaluasi Model Context, Input, process, $\quad \operatorname{product}(C I P P)$ merupakan hasil kerja para tim peniliti, yang tergabung dalam 
suatu organisasi komite PHI

DELTA KAPPA USA, yang diketuai oleh Daniel Stuffle-Beam. Model CIPP ini juga termasuk model yang tidak terlalu menekankan pada tujuan suatu program. Model CIPP pada prinsipnya konsisten dengan definisi evaluasi program pendidikan yang diajukan oleh komite tentang "Tingkat untuk menggambarkan pencapaian dan menyediakan informasi guna pengambilan keputusan alternatif" (Sukardi, 2009:63)

Menurut Hasibuan (2009:3), pentingnya sebuah manajemen diterapkan di dalam sebuah organisasi, karena pada dasarnya kemampuan manusia itu terbatas (fisik, pengetahuan, waktu,dan perhatian) sedangkan kebutuhannya tidak terbatas. Usaha untuk memenuhi kebutuhan dan terbatasnya kemampuan dalam melakukan pekerjaan mendorong manusia membagi pekerjaan, tugas dan tanggung jawab. Dengan adanya pembagian kerja, tugas, dan tanggung jawab ini maka pekerjaan yang berat dan sulit akan dapat diselesaikan dengan baik serta tujuan dapat tercapai. Sehingga pola pembinaan pretasi shotokai kabupaten Nagekeo dapat berjalan dengan baik.

\section{METODE PENELITIAN}

Metode penelitian yang digunakan dalam penelitian ini adalah evaluasi program menggunakan model CIPP (context-input-prosess-product).

Model ini dikembangkan oleh Stufflebeam 1971 (dari Ward Mitchell Cates, 1995). Model CIPP (context-input-prosess-product) ini melihat empat dimensi yaitu dimensi konteks, dimensi input, dimensi prosses dan dimensi produk. Artinya untuk memperoleh informasi yang akurat dan obyektif serta membandingkan apa yang telah dicapai dari program pembinaan cabang olahraga bela diri sotokai kabupaten Nagekeo, dengan apa yang seharusnya dicapai berdasarkan standart atau tujuan yang telah ditetapkan.

Data primer yang diperoleh dalam penelitian ini menggunakan alat pengumpul data berupa observasi, wawancara, sedangkan dokumentasi berupa arsip yang ada digunakan sebagai data pendukung atau data sekunder (Arikunto, 2010:172) Instrumeninstrumen inilah yang digunakan untuk memperoleh data tentang program pembinaan cabang olahraga sotokai kabupaten.

Subyek penelitan ini adalah pengurus, pelatih, atlet dan yang terkait lainya. Dalam pengambilan sampel peneliti menggunakan teknik purposive sampling. Teknik purposive sampling adalah 
pengambilan sampel sumber data dengan pertimbangan tertentu (Sugiyono,2010:54). Sampel yang dipilih dalam metode kualitatif lebih ditekankan pada tujuan agar informasi didapat secara maksimal dan akurat.

Sumber data yang digunakan dalam penelitian ini diperoleh dari 1).Place (Tempat latihan, sarana dan prasarana, kegiatan selaentang atlet, pelatih, majalah, buku dan lain-lain di cabang olahraga sotokai kabupaten Nagekeo latihan), 2).Person (Pengurus, pelatih, atlet,), 3).Paper (Dokumen $\mathrm{t}$ ). Analisis data yang digunakan dalam penelitian ini adalah analisis deskriptif kualitatif, artinya menganalisis hasil temuan di lapangan pembinaan prestasi cabang olahraga sotokai kabupaten Nagekeo.

\section{HASIL PENELITIAN}

Evaluasi context meliputi aspek:1) visi, 2) Misi, 3) Tujuan pembinaan, 4) Dukungan/kebijakan pemerintah. Visi sotokai Nagekeo merupakan harapan yang ingin dicapai yaitu mengharapkan prestasi atlet-atlet sotokai Nagekeo prestasi baik ditingkat daerah, nasional maupun ditingkat Internasional

Evaluasi input dalam penelitian ini akan menjelaskan tentang bagaimana seleksi Pelatih, seleksi Atlet, sarana prasarana dan dana pada cabang olahraga sotokai Nagekeo Hasil analisis tentang seleksi pelatih baik karena proses seleksi pelatih shotokai Nagekeo memenuhi syarat dan ketentuan yang berlaku yaitu harus mempunyai lisensi dan sertifikat minimal tingkat daerah sampai pada tahap Nasional, sehingga dari data yang diperoleh pelatih sotokai Nagekeo memperoleh lisensi Nasional dan sering menjadi wasit pada kejuaraan tingkat nasional. Seleksi atlet juga baik karena atlet sotokai Nagekeo diseleksi berdasarkan syarat dan ketentuan yang berlaku oleh dinas Pemuda dan Olahraga Kabupaten Nagekeo serta oleh induk organisasi shotokai Nagekeo. Sarana dan prasarana merupakan faktor pendukung keberhasilan pembinaan prestasi olahraga. Saat ini sarana dan prasarana masih sangat kurang yang dimiliki oleh cabang olahraga shotokai, sehingga keberhasilan prestasi atlet sotokai juga turut mempengaruhinya, Dana merupakan salah satu faktor yang mendukung hasilnya pembinaan karena tanpa adanya dana, maka pembinaan akan sulit berjalan kearah pretasi yang maksimal, berdasarkan hasil temuan dilapangan bahwa dana yang diperoleh semuanya bersumber dari dukungan pemerintah daerah kabupaten Nagekeo sehingga 


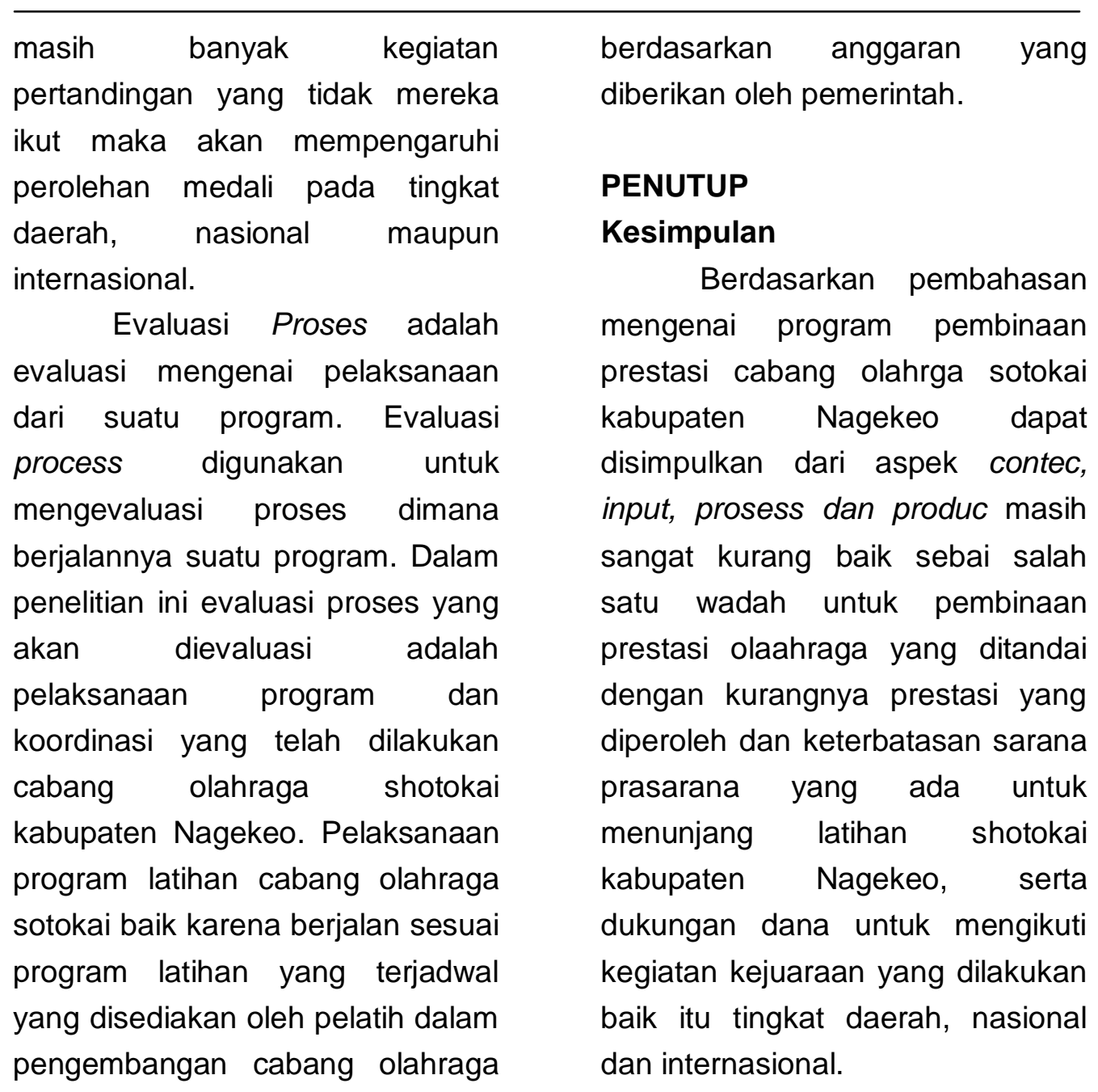

sotokai kabupaten nagekeo sehingga dari program yang ada dapat mendukung kemajuan dalam latihan, serta Ada koordinasi yang baik antara pengurus, pemerintah pelatih dan atlet, maupun pihakpihak terkait cabang olahraga shotokai kabupaten Nagekeo.

Hasil analisis tahap product pada cabang olahraga shotokai Kabupaten Nagekeo dikategorikan kurang dalam perolehan medali karena keterbatasan anggaran yang dikuncurkan oleh pemerintah sehingga dalam mengikuti kejuaraan yang dilaksanakan

\section{Saran}

Berdasarkan dari hasil penelitian dan pembahasan, dapat diajukan beberapa rekomendasi atau saran, yaitu :

1) Pembinaan prestasi shotokai harus dapat lebih aktif serta meningkatkan program pembinaan yang baik sehingga lebih diperhatikan lagi oleh pemerintah atau pihak-pihak yang bersangkutan pada kabupaten Nagekeo

2) Penegelola dan pengurus cabang olahraga sotokai 
Nagekeo harus lebih giat dalam pemantauan terkait sarana dan prasarana yang diberikan pemerintah dalam hal pemeliharaan dan pengadaan yang masih kurang, sehingga dapat melancarkan segala kegiatan yang diselenggarakan oleh induk organisasi shotokai kabupaten Nagekeo, serta pemerintah harus memperhatikan secara baik dengan memberikan penghargaan bagi atlet shotokai Nagekeo yang menunjukan prestasi.

\section{DAFTAR PUSTAKA}

Arikunto, Suharsimi. 2010. Prosedur Penelitian: Suatu Pendekatan Praktik. Jakarta: Rineka Cipta.

Arikunto,S \& Cepi, S.A.J. 2009. Evaluasi Program Pembinaan. Jakarta: Bumi Aksara
B Wani. 2018. Evaluasi Program pembinaan prestasi atlet tinju pada pusat pembinaan latihan olahraga pelajar provinsi Nusa tenggara timur, Jurnal ilmiah pendidikan citra bakti, vol 5 No. 1. Ngada: STKIP Citra Bakti

Harsuki. 2012. Pengantr manajemen olahraga. Jakarta:PT raja grafindo

Hasibuan, S.P. Malayu, 2009. Manajemen Sumber Daya Manusia, cetakan ketujuh Penerbit PT Bumi Aksara, Jakarta

Sugiyono. 2010. Metode Penelitian Pendidikan. Bandung: Alfabeta.

Sukardi. 2009. Evaluasi Pendidikan Prinsip \& Operasionalnya, Yogyakarta, PT Bumi Aksara.

Undang-Undang No. 3, Tahun 2005, Tentang Sistem Keolahragaan Nasional, Jakarta: Kementrian Negara Pemudadan Olahraga 